\title{
O QUE DIZEM SOBRE GÊNEROS TEXTUAIS PROFESSORES DE LÍNGUA PORTUGUESA EGRESSOS DO PROGRAMA DE FORMAÇÃO CONTINUADA GESTAR ॥
}

\author{
WHAT DO THE PORTUGUESE TEACHERS WHO PARTICIPATED OF A \\ CONTINUING EDUCATION PROGRAM (GESTAR II) SAY ABOUT TEXTUAL \\ GENRES?
}

\author{
SOMBRIO, Leila Mattos \\ leilasombrio@gmail.com \\ Universidade da Região de Joinville \\ KOERNER, Rosana Mara \\ rosanamarakoerner@hotmail.com \\ Universidade da Região de Joinville
}

RESUMO: O objetivo do presente estudo foi constatar as percepções de professores de Língua Portuguesa sobre o Programa GESTAR II (Programa Gestão da Aprendizagem) e sua contribuição para o trabalho com gêneros textuais/discursivos. Identificaram-se os professores que participaram do GESTAR II, depois, por meio de carta endereçada à escola na qual trabalhavam, apresentou-se a pesquisa e o convite a participarem juntamente com um questionário. Dos 53 participantes, egressos do programa, dez responderam e devolveram o instrumento de pesquisa. O questionário era composto por 13 questões: dez fechadas e três abertas, com perguntas sobre os sujeitos (tempo no magistério, formação, entre outros aspectos) e sobre como avaliam o programa em diversos aspectos (horário das aulas, materiais utilizados, formadores etc.). Buscando indícios do trabalho e concepção sobre gêneros, mais especificamente na última questão $\left(13^{\mathrm{a}}\right)$, havia a proposta para que os participantes respondessem/escrevessem um balanço do saber (técnica que consiste na resposta de um enunciado). A análise dos dados revelou uma avaliação bastante positiva do programa, por parte dos professores, especialmente pela relação possível com a prática pedagógica. Quanto às concepções sobre gêneros, percebeu-se que as respostas dos professores refletem os conceitos pressupostos do material disponibilizado pelo GESTAR, perceptível especialmente no uso de determinados termos, tidos como chave. O Programa parece ter contribuído para o esclarecimento de questões relacionadas ao conceito de gênero, com aspectos passíveis de ser transpostos para o espaço da sala de aula. Principais autores que dão sustentação teórica ao trabalho: Bakhtin (2000 [1952, 1953]), Imbernón (2001, 2010), Gatti (2008), André (1986, 2010) e Nóvoa (2002).

PALAVRAS-CHAVES: Formação continuada. GESTAR II. Gêneros textuais/discursivos. Trabalho docente. 
ABSTRACT: The theme of this research relates to verify the perceptions of continuing education for teachers of Portuguese, regarding the conception of textual / discursive genres. The purpose is to raise the notions about textual/ discourse genres of Portuguese Language teachers, who had concluded the program GESTAR II (Learning Management Program), through a qualitative approach. At first, we identified the teachers who had participated in the GESTAR II. Later, through a letter addressed to the school in which they work, the research was presented and an invitation was made for the teachers to participate along with a questionnaire. Of the 53 program participants, ten answered and returned the survey instrument. The questionnaire consisted of 13 questions: ten closed and three open questions on the subject (time in the teaching profession, training and so on) and how to evaluate the program in several aspects (schedule of classes, materials, trainers, etc.). Seeking evidence of work and notions on genre, specifically in the last question (13th), the proposal was for participants to respond/write a knowledge inventory (a response technique, which consists of giving an answer based on a statement). Data analysis revealed a fairly positive assessment of the program by teachers, especially the possible relationship with the pedagogical practice. The material, as well as trainers, was evaluated as of good quality. Regarding conceptions about genre, it was found that teachers' responses reflect the assumed concepts of the material made available by GESTAR, especially noticeable in the use of certain terms, seen as keywords. The program seems to have contributed to the clarification of issues related to the concept of genre, with aspects that could be transferred to the classroom environment. Major authors that give theoretical support to the work: Bakhtin (2000 [1952, 1953]), Imbernon (2001, 2010), Gatti (2008), André (1986.2010) and Nóvoa (2002).

KEYWORDS: Continuing Education. Textual/discursive genres. GESTAR II.

Teacher's work.

\section{INTRODUÇÃO}

A formação continuada, direcionada a professores em exercício, busca atender às necessidades que surgem ou pela prática ou por legislações/convenções sociais. Muitas vezes os novos conhecimentos são incluídos nos currículos das licenciaturas, mas os professores já graduados precisam de formação adicional e contínua para obtê-los. Segundo Libâneo (2004, p.227):

O termo formação continuada vem acompanhado de outro, a formação inicial. A formação inicial refere-se ao ensino de conhecimentos teóricos e práticos destinados à formação profissional, completados por estágios. A formação continuada é o prolongamento da formação inicial, visando o aperfeiçoamento profissional teórico e prático no próprio contexto de trabalho e o desenvolvimento de uma cultura geral mais ampla, para além do exercício profissional. 
Nesse sentido, por sua importância na profissionalização do docente, a formação continuada constitui-se como um interessante campo de pesquisa. Em consulta a sites de busca (Capes e SCielo) observou-se que não há número expressivo de pesquisas relacionadas ao GESTAR. Mesmo sendo um programa do Governo Federal, instituído em diversos municípios brasileiros, atendendo e formando algumas centenas de professores, há poucas pesquisas que analisem suas contribuições.

A partir de tais considerações, chegou-se à temática de pesquisa, com o seguinte objetivo: verificar o que dizem professores de Língua Portuguesa, egressos do Programa GESTAR II (Programa Gestão da Aprendizagem Escolar) sobre gêneros textuais/discursivos ${ }^{1}$. Mais especificamente, são buscados indícios das orientações teórico-metodológicas do programa GESTAR II relativas ao trabalho com os gêneros em sala de aula. Assim, o presente trabalho foi orientado pela seguinte questão de investigação: Há indícios das discussões proporcionadas pela formação continuada (no que tange ao trabalho com os gêneros textuais/discursivos) na descrição de uma prática pedagógica dos professores participantes da formação continuada GESTAR II?

Esta pesquisa tem sua principal justificativa na compreensão do quanto um programa de formação continuada pode contribuir para o desenvolvimento profissional do professor no que tange à reflexão sobre concepções teóricometodológicas que irão subsidiar o seu fazer pedagógico. É de suma relevância perceber quais os reflexos que um programa (como o GESTAR II) deixa no dizer dos professores, com base em sua prática, no caso do presente estudo, aquela que envolve o trabalho com os gêneros textuais/discursivos.

\section{ALGUMAS CONSIDERAÇÕES INICIAIS SOBRE O GESTAR E O TRABALHO COM OS GÊNEROS TEXTUAIS/DISCURSIVOS}

A formação continuada pode ser parte significativa na constituição do desenvolvimento do professor. Com o reconhecimento da complexidade da profissão docente, com os resultados de estudos permanentes na área e com a

\footnotetext{
${ }^{1}$ Para este trabalho será adotada a expressão textual/discursivo, isso porque o material utilizado na formação continuada (foco desta pesquisa) usa indistintamente ora textual, ora discursivo.
} 
inserção de novas legislações, a formação continuada é oferecida para não somente atualizar os profissionais em exercício, mas principalmente para propor reflexões pertinentes à área, como sugere Nóvoa (2002). Por isso é importante que a formação continuada seja algo ininterrupto, como aponta Imbernón (2010, p.67, grifo nosso): "[...] a formação inicial deve preparar para uma profissão que exige que se continue a estudar durante toda a vida profissional [...]".

Como apontou Imbernón, ser professor pressupõe estudar - e sempre! -, o que inviabiliza a crença de que, ao concluir o curso superior, este profissional estaria plenamente apto para ingressar na escola e enfrentar todos os desafios propostos. Como nos diz Vasconcellos (2006, p.123), ao tratar do cotidiano da sala de aula: "[...] mesmo quem saiu dos melhores centros universitários sabe que não domina tudo que a atividade educativa exige, tendo necessidade de aprimoramento contínuo".

É importante ressaltar que, embora tenha caráter de atualização, não é (ou melhor, não deveria ser) apenas com esta função que as formações acontecem. A formação continuada não deve ser considerada como um aglomerado de palestras, seminários e cursos, mas sim como uma oportunidade de reflexão, de construção e desconstrução de teorias e práticas.

Pelo que foi exposto até aqui, parece possível depreender que a formação continuada priorize o real do professor, sua prática e contexto. Precisa responder e proporcionar reflexões que digam respeito, diretamente, à prática do professor atuante.

Em uma busca na página virtual da CAPES ${ }^{2}$, entre os anos 2009 e 2011, das 792 dissertações que tratavam de formação continuada, apenas seis abordavam o GESTAR. Com relação às teses, nenhuma das 209 teses tratava do referido programa. O mesmo aconteceu em consulta à página virtual Scielo (Scientific Eletronic Library Online), na qual é possível consultar artigos resultantes de pesquisa científica: nenhum dos 206 trabalhos publicados sobre formação continuada tinha relação com o programa GESTAR.

Esse breve balanço das produções demonstra, principalmente, um baixo número de pesquisas relacionadas à temática (6 dissertações), o que pode ter

${ }^{2}$ CAPES - Coordenação de Aperfeiçoamento de Pessoal de Nível Superior 
relação com o fato de que o GESTAR é um programa recente (lançado em 2008) e também ao fato de que o programa, embora tenha sido oferecido pelo MEC, não aconteceu em todos os municípios brasileiros.

O Programa GESTAR II oferece formação continuada em Língua Portuguesa e Matemática aos professores dos anos finais (do sexto ao nono ano) do ensino fundamental em exercício nas escolas públicas. A formação possui carga horária de 300 horas, sendo 120 horas presenciais e 180 horas a distância (estudos individuais) para cada área temática. $O$ programa inclui discussões sobre questões prático-teóricas e busca contribuir para o aperfeiçoamento da autonomia do professor em sala de aula. Foi oferecido, por meio dos gestores escolares, a todos os professores de Língua Portuguesa e Matemática do ensino fundamental, anos finais (do sexto ao nono ano), nos anos de 2009, 2010 e 2012, de uma cidade ao norte de Santa Catarina, com a $3^{a}$ maior rede de ensino do sul do país. No que concerne à Língua Portuguesa ${ }^{3}$, em 2009, 36 professores participaram da formação; já em 2010, 17 professores.

Caracterizado por ser considerado um programa de formação continuada em exercício, o foco do programa, segundo o Guia Geral (2008, p.14), é "a atualização dos saberes profissionais por meio de subsídios e do acompanhamento da ação do professor no próprio local de trabalho." Baseia-se nos PCNs de Matemática e de Língua Portuguesa do Ensino Fundamental. Tem por finalidade, de acordo com o referido Guia, elevar a competência dos professores e dos alunos e, por consequência, melhorar as capacidade de compreender e intervir sobre/na realidade sociocultural.

O GESTAR é considerado semipresencial e é fundamentado pela teoria e pressupostos da educação a distância (foco na autonomia do estudante). Os encontros presenciais do programa preveem atividades como:

- troca de experiências e reflexão individual e em grupos;

- esclarecimentos de dúvidas e questionamentos;

- planejamento e elaboração de situações didáticas;

- análise crítica da prática em sala de aula e de atividades dos alunos. (BRASIL, 2008, p. 15)

\footnotetext{
${ }^{3}$ Optou-se por língua portuguesa por ser a área de formação das autoras.
} 
O material utilizado tem característica teórico-prática, que permite e estimula o estudo autônomo e independente. O programa GESTAR II tem como objetivos:

\footnotetext{
Colaborar para a melhoria do processo ensino-aprendizagem dos alunos nas áreas temáticas de língua portuguesa e matemática;

Contribuir para o aperfeiçoamento da autonomia do professor na sua prática pedagógica;

Permitir ao professor o desenvolvimento de um trabalho baseado em habilidades e competências. (BRASIL/MEC, 2008, p. 06)
}

A publicação dos $\mathrm{PCNs}$ traz à tona a temática dos gêneros textuais como proposta de mediação do ensino de Língua Portuguesa e é sob esta ótica que se baseia (ou deveria basear-se) o ensino de língua atual. É este documento que orienta o material do GESTAR.

Com relação às questões relacionadas ao gênero, faz-se necessário retomar a significativa contribuição de Bakhtin. Embora as obras do círculo bakhtiniano tenham tido alguns percalços de divulgação e tradução (RODRIGUES, 2005), são elas que fundamentam as questões sobre gênero textual/discursivo, em uma perspectiva dialógica e discursiva da linguagem, dos PCNs, como indica Brait (2000), lembrando que não há referências explícitas ao autor no referido documento. Situações de comunicação oral e escrita estão sempre (ou quase sempre) categorizadas em um gênero, por suas formas padrão e relativamente estáveis. Dessa forma, é sempre por meio de algum gênero que ocorre o uso de uma língua, mesmo que os falantes não tenham consciência disso. Para Bakhtin (2000, p. 279) a utilização da língua ocorre "[...] em forma de enunciados (orais e escritos), concretos e únicos, que emanam dos integrantes duma ou doutra esfera da atividade humana".

Sob esta perspectiva, é possível dizer que a utilização dos gêneros pode ser considerada uma ferramenta para o trabalho com a língua, conforme Marcuschi (2003, p. 35),

[...] o trabalho com gêneros textuais é uma extraordinária oportunidade de se lidar com a língua em seus mais diversos usos autênticos no dia a dia. Pois nada do que fizermos linguisticamente estará fora de ser feito em algum gênero. Assim, tudo o que fizermos linguisticamente pode ser tratado em um ou outro gênero. $E$ há muitos gêneros produzidos de maneira sistemática e com grande incidência na vida diária, merecedores de nossa atenção. 
As ideias de um trabalho com a língua baseado nos gêneros, como proposto por Bakhtin, ganham notoriedade com a publicação dos PCNs. Nesse documento, as discussões sobre os gêneros textuais/discursivos receberam intenso foco, principalmente no que concerne ao ensino de Língua Portuguesa:

Todo texto se organiza dentro de determinado gênero em função das intenções comunicativas, como parte das condições de produção dos discursos, as quais geram usos sociais que os determinam. [...] (BRASIL, 1999, p.21).

As principais discussões sobre gênero textual partem da premissa proposta por Bakhtin (2000), de que só é possível se comunicar por meio de gêneros. Dessa forma, o ensino de Língua Portuguesa centrado nos gêneros possibilita aos estudantes a compreensão da função social e comunicativa de cada texto, independentemente da linguagem (se verbal, não-verbal ou sincrética):

No processo de ensino-aprendizagem dos diferentes ciclos do ensino fundamental espera-se que o aluno amplie o domínio ativo do discurso nas suas diversas situações comunicativas, sobretudo nas instâncias públicas de uso da linguagem, de modo a possibilitar sua inserção efetiva no mundo da escrita, ampliando suas possibilidades de participação social no exercício da cidadania. (BRASIL, 1999, p.32).

A publicação dos PCNs (1998) sugere que o trabalho com a língua considere o uso que os alunos fazem dela. Para tanto, é necessário compreender este aluno como um sujeito histórico inserido em uma sociedade (grafocêntrica) na qual o uso da língua (especialmente a modalidade escrita) assume diferentes funções e possui diferentes características.

O propósito do ensino de língua materna, além de tornar os alunos fluentes, é capacitá-los a utilizar a língua de modo variado, com o intuito de produzir diferentes efeitos de sentido, adequando o uso da língua às situações sociais diversas. Ou seja, a prática do professor de língua, na maior parte das vezes, deve estar intimamente ligada à concepção de gênero textual/discursivo e, visto a função comunicativa da língua, também é possível afirmar que os gêneros preveem aspectos sociais de interação. Considerando a diversidade (quase infinita, nos termos de Bakhtin) dos gêneros, a recomendação dos PCNs é priorizar "[...] aqueles cujo domínio é fundamental à efetiva participação social, encontrando-se agrupados, em função de sua circulação social [...]" (BRASIL, 1999, p. 53). Assim, os gêneros 
privilegiados e sugeridos para o trabalho apresentam-se organizados em tabelas divididas entre linguagem oral e linguagem escrita e categorizados em "função de sua circulação social": literários, de imprensa, publicitários e de divulgação científica. Contudo, não se trata de uma "lista" fechada; o próprio documento aponta que “...outras escolhas poderão ser feitas" (BRASIL, 1999, p. 53).

Portanto, tem-se como proposta de trabalho para o ensino de língua materna uma abordagem que considera os variados gêneros textuais/discursivos como ferramenta de ensino, pois é por meio da língua, consequentemente, por meio dos gêneros, que o ser humano interage, comunica-se, constrói e divulga conhecimentos, ou seja, sempre está pautado em uma perspectiva dialógica. Schneuwly e Dolz (1999, p.7) propõem a ideia de gênero como "mega-instrumento", pois "[...] fornece um suporte para a atividade nas situações de comunicação e uma referência para os aprendizes." Os referidos autores apresentam a noção de Sequência Didática, assumida em alguns materiais que orientam o ensino a partir dos gêneros. De acordo com os autores, com colaboração de Noverraz, "Uma 'sequência didática' é um conjunto de atividades escolares organizadas, de maneira sistemática, em torno de um gênero textual oral ou escrito." (DOLZ; SCHNEUWLY e Colaboradores, 2004, p.97).

O Programa GESTAR pode se caracterizar como um projeto de formação continuada (em serviço) que objetiva preencher lacunas advindas da formação inicial. Sendo a base do programa discussões teórico-práticas ${ }^{4}$, o eixo norteador de tais discussões foi o ensino de Língua Portuguesa por meio de gêneros textuais/discursivos.

Como orienta o próprio Guia, o uso da língua é privilegiado nos cadernos de Teoria e Prática (materiais dos professores cursistas) como sendo uma atividade social e comunicativa. Dessa forma, o texto é visto como "a concretização das situações de interação e um produto de condições sócio-históricas, em que a significação é o ponto central." (BRASIL, 2008, p.38). É possível afirmar que a concepção de língua e de texto tem relação com a premissa bakhtiniana, visto a

\footnotetext{
${ }^{4}$ Tem-se como exemplo um trecho da parte da apresentação do caderno Teoria e Prática 1: "Assim, vamos não só discutir conceitos como variação linguística, texto, intertextualidade, gramática, arte e literatura, gêneros textuais, mas vamos mostrar como esses conteúdos podem e devem entrar nas suas aulas para alunos dos $3^{\circ}$ e $4^{\circ}$ ciclos." (BRASIL, 2008, p.7, (grifo nosso).
} 
ênfase dada ao caráter social e comunicativo da língua e a consideração do espaço histórico-cultural dos interlocutores.

Os cadernos de Teoria e Prática são divididos por temas e cada tema conduz a seleção de textos utilizados nas seções, dos mais diversos gêneros textuais/discursivos. Tais cadernos são utilizados principalmente nos momentos presenciais do curso, sob orientação do professor formador, embora tenha diversas "lições de casa" para os professores cursistas. Já nos Cadernos de Atividades de Apoio à Aprendizagem (AAA), com exemplar tanto para os alunos como para os professores, as atividades a serem desenvolvidas são organizadas por Unidades e, dentro das Unidades, divididas por Aulas. Nestes cadernos, o professor recebe indicações de como trabalhar com o aluno, de modo muito próximo ao que ele mesmo vivenciou a partir do que Ihe foi proposto no caderno Teoria e Prática.

Com relação aos cadernos da temática "Gêneros e Tipos Textuais" (especialmente o TP3), que mais interessam ao presente estudo, apresentam concepções sobre língua, linguagem, tipos e gêneros textuais.

As unidades são organizadas de maneira didática, iniciando com a discussão teórica sobre os gêneros e com o trabalho possível de ser realizado a partir daí. Depois o material discute a relação com os tipos textuais, ponto que geralmente oferece certa dificuldade já que a noção de texto se encontra bastante impregnada nos livros didáticos.

São vários os enunciados que abordam o conceito de gênero: "maneira de organizar as informações linguísticas do texto" (p. 25), "enunciados relativamente estáveis, mas não estáticos" (p. 30), "realizações linguísticas concretas definidas por propriedades sociocomunicativas" (p. 32), "padrões relativamente estáveis de enunciados presentes em cada interação verbal" (p. 68). É possível reconhecer alguns termos utilizados por Bakhtin, como: "relativamente", "estáveis", "enunciados". Há uma significativa recorrência a estas expressões, parecendo sugerir a necessidade de que a ideia seja, de fato, assimilada.

Também quando o material diz como os gêneros se distinguem, os termos de Bakhtin são explicitamente utilizados: "Distinguem-se pelo conteúdo temático, pelo estilo, pela composição textual, pelo relacionamento social dos participantes e, especialmente, pela finalidade segundo a qual são produzidos." (p.68, grifos nossos). 
Há significativa preocupação com a relação entre gêneros e a competência sociocomunicativa, considerando as condições de produção e o reconhecimento dos gêneros apropriados, e o interlocutor a que se destina o enunciado, assim como nos diz Bakhtin (2003 [1952, 1953], p. 301):

O querer-dizer do locutor se realiza acima de tudo na escolha de um gênero discursivo. Essa escolha é determinada em função da especificidade de uma dada esfera da comunicação verbal, das necessidades de uma temática (do objeto do sentido), do conjunto constituído dos parceiros, etc. Depois disso, o intuito discursivo do locutor, sem que este renuncie à sua individualidade e à sua subjetividade, adapta-se e ajusta-se ao gênero escolhido, compõe-se e desenvolve-se na forma do gênero determinado.

É possível perceber tal preocupação, também, no material do GESTAR, como se destaca abaixo:

O contato com textos no nosso dia-a-dia exercita nossa capacidade de reconhecer os fins para os quais este ou aquele texto é produzido. O nível de linguagem, o jogo entre conteúdos explícitos e implícitos, o respeito às relações de interlocução tornam, assim, um texto adequado ou não a sua situação de produção/leitura.

Essas são características que definem o uso de um determinado gênero. Ninguém com um certo desenvolvimento da competência sociocomunicativa pensaria, por exemplo, em escrever um requerimento para pedir que lhe fosse passada a jarra de água à mesa do jantar - a não ser que se tratasse de uma brincadeira. A modalidade escrita e o gênero textual seriam inapropriados para a ocasião. Percebe-se ser, assim, impossível desvincular o gênero textual da situação em que é utilizado o texto.

Recorte digital do caderno Teoria e Prática 3, p.27

No material, o texto é concebido como "[...] toda e qualquer unidade de informação no contexto de interação; entendendo-se interação como uma ação entre sujeitos, entre interlocutores." (TP3, p.19). Há uma significativa preocupação com a distinção entre gênero e tipo textual, que ocupa duas das quatro unidades que compõem o material.

Tal ênfase parece indicar o reconhecimento de que a noção de texto, como estrutura narrativa, descritiva ou dissertativa, por tanto tempo se fez presente nos manuais para o ensino da Língua Portuguesa e que certamente se encontra impregnada nas concepções dos professores, como apontado no próprio material: "Os tipos textuais são mais conhecidos que os gêneros na tradição escolar, especialmente nas aulas de redação, quando trabalhamos com a descrição, a 
narração e a dissertação." (p. 98). O material propõe como um dos objetivos: "Relacionar sequências tipológicas à classificação de gêneros." (p. 142).

Em suma, a partir desta breve análise, percebe-se que as ideias de Bakhtin permeiam o material do GESTAR (ainda que não plenamente), especialmente no que concerne à temática dos gêneros, presente no Caderno Teoria e Prática 3. Considerando o foco deste estudo, olhar para este material se fez necessário para buscar indícios de suas discussões nos dizeres dos professores.

\section{O PERCURSO METODOLÓGICO}

A amostra constituiu-se por parte dos professores de língua portuguesa, participantes egressos da formação continuada GESTAR II (realizada nos anos de 2009 e 2010) que fossem atuantes na rede pública de uma cidade ao norte de Santa Catarina, independentemente da situação contratual (se concursados/efetivos ou contratados), do tempo de serviço na rede, da formação, do sexo e da idade.

Levando em conta o contexto social e os objetivos, o presente estudo apresenta-se com uma abordagem qualitativa. Para Gatti e André (2010, p. 30) este tipo de abordagem constitui-se:

[...] em uma modalidade investigativa que se consolidou para responder ao desafio da compreensão dos aspectos formadores/formantes do humano, de suas relações e construções culturais, em suas dimensões grupais, comunitárias ou pessoais.

A vantagem da abordagem qualitativa está na possibilidade de avaliar os sujeitos e dados de maneira contextualizada, analisando questões implícitas de suas respostas, bem como considerar a complexidade que envolve as relações humanas.

Como instrumentos para a coleta de dados foram utilizados: um questionário com 13 perguntas: nove fechadas e quatro abertas, uma das questões abertas sugeria que os professores escrevessem uma produção textual (balanço do saber) a respeito de suas concepções sobre gênero. Foram enviados 53 questionários número total de egressos do GESTARII dos anos 2009 e 2010. Desses, 10 foram devolvidos e todos foram considerados válidos.

As perguntas básicas e fechadas foram a respeito do tempo de serviço, formação, titulação e informações específicas relativas ao GESTAR II e perguntas 
abertas para a descrição de algumas práticas e materiais que os sujeitos da pesquisa têm utilizado no ensino de língua portuguesa, buscando indícios do trabalho e concepção dos gêneros textuais. Uma das perguntas abertas é caracterizada como balanço do saber.

O balanço do saber, segundo Charlot (2001), objetiva que os participantes da pesquisa avaliem seus processos de aprendizagem. Trata-se da produção de um texto fundamentado em um enunciado que é elaborado de maneira especial para obter dados a respeito do objeto de pesquisa. A proposta de escrita do balanço do saber tem seu foco na formação continuada GESTAR II, especialmente no que diz respeito à concepção sobre gênero textual/discursivo.

A análise dos dados fundamentou-se em Bakhtin (1992) na perspectiva dialógica, na qual se estabelece relação entre o material do programa GESTAR II, as respostas dos participantes e a interlocução teórica observando-se as concepções dos professores sobre o que é gênero textual/discursivo.

Para análise das respostas obtidas com o balanço do saber, utilizou-se a análise de conteúdo que, conforme Bardin (1977, p. 42), constitui-se como:

\begin{abstract}
Um conjunto de técnicas de análise das comunicações visando obter, por procedimentos sistemáticos e objetivos de descrição do conteúdo das mensagens, indicadores (quantitativos ou não) que permitam a inferência de conhecimentos relativos às condições de produção/recepção (variáveis inferidas) destas mensagens.
\end{abstract}

Primeiramente, criou-se um plano de análise, no qual estavam previstas a análise das respostas do sujeito em sua individualidade e, ao mesmo tempo, do conjunto de respostas obtidas a cada questão. Para isso, fez-se uma cópia de cada questionário e identificou-se com os nomes fictícios de cada respondente (professor A, B, C e assim por diante). Depois, a resposta de cada respondente a cada uma das questões foi recortada e separada, formando um agrupamento, tornado visível em um cartaz. Dessa forma, foi possível tanto visualizar a recorrência de termos nas respostas quanto observar todas as respostas de cada um dos respondentes.

Sobre os sujeitos, foram solicitadas informações relativas à sua formação, tempo de serviço e participação na formação continuada, sem qualquer tipo de identificação. 


\subsection{Perfil dos professores pesquisados (questões 1 a 5)}

Com relação ao tempo de serviço na área da educação, apenas um professor está em início de carreira. Os demais já têm mais de cinco anos. A resposta com maior incidência é "Mais de 21 anos" (três professores). Vale lembrar que foram os Parâmetros Curriculares Nacionais (PCNs), em 1998, que trouxeram para as escolas brasileiras a noção de gêneros textuais (embora a discussão sobre a temática tenha surgido antes, com Bakhtin - 1952,1953). A obra de Bakhtin (2000 [1952,1953]) fundamenta, pelo menos em parte, as questões sobre gêneros textuais dos PCNs (ROJO, 2000, p.11). Ou seja, metade desses sujeitos (cinco: $F, G, H, I, J$ ), tiveram sua formação e inserção profissional na área da educação antes da publicação dos PCNs, o que pode exercer grande influência na concepção de língua dos sujeitos e, consequentemente, de gênero.

Sobre a formação dos professores, solicitou-se a descrição do curso superior e o ano de conclusão. Sete professores informaram ser graduados em Letras, entre os anos 1983 e 2002. Os respondentes A, G e J não marcaram a opção de curso superior. Talvez, já que marcaram a especialização, tenham compreendido que a pergunta requeria apenas o nível mais alto de escolaridade. Quanto à especialização (pós-graduação), nove dos dez professores afirmam ter participado entre os anos 1994 e 2012.

\subsection{O programa GESTAR II na voz dos professores}

As questões 06, 07, 08 e 09 requeriam informações específicas sobre o programa de formação continuada em questão: GESTAR II. Tais questões tinham por objetivo avaliar os principais aspectos da formação oferecida: horário das aulas, ambiente de estudo, materiais utilizados, formadores, concepções teóricometodológicas e orientações práticas.

O aspecto "horário das aulas" obteve maior número de respostas (40\%) no item "insatisfatório". O professor $\mathrm{J}$ especificou ainda que, após trabalhar o dia inteiro, tinham que fazer o curso à noite e, segundo o mesmo professor, "Era muito cansativo". Estes dados remetem à reflexão sobre o horário escolhido para as 
formações (em ambos os anos, pois há professores do grupo de 2009 e também de 2010 na resposta "insatisfatório").

Para estes professores, frequentar a formação exigiu mais do que a dedicação de algumas horas fora do horário de trabalho. Talvez tenha exigido que os professores deixassem seus filhos com pessoas estranhas, ou ainda, que mudassem sua rotina. Quem sabe, este quesito tenha contribuído no baixo número de adesão ao curso: dos 183 professores de língua portuguesa da rede, apenas 53 participaram do curso (total dos dois anos), que representou $29 \%$.

Com relação ao item "ambiente de estudo", a maior parte dos participantes (60\%) julgou "satisfatório". Trinta por cento (30\%) dos professores avaliaram "bom", e apenas $10 \%$ (o que representa um participante) consideraram "muito bom". Nenhum dos participantes respondeu "excelente".

A avaliação dos formadores considerava dois aspectos: conhecimento e didática. De maneira geral, os formadores foram bem avaliados. A maior parte dos respondentes assinalou a opção: "Atendeu às minhas expectativas”.

Como já mencionado anteriormente, o material do programa organiza-se a partir do disposto nos PCNs e das contribuições de Bakhtin, especialmente no que se refere à questão do contexto sociocomunicativo, cenário em que ocorrem as manifestações dos gêneros textuais/discursivos. Oito (80\%) participantes julgaram que tais concepções são "Passíveis de transposição (teoria X prática)". Os dois (20\%) outros professores, sobre as concepções teórico-metodológicas, consideram que "Foram esclarecidas".

Tais respostas reforçam o fato de que os professores avaliaram positivamente o material utilizado. De fato, o material possui claramente orientações sobre como "aplicar" o que está sendo visto. Até mesmo o modo de organização do GESTAR, em que o professor participa dos encontros e é instado a preencher um caderno denominado Teoria e Prática, favorece tal reconhecimento. Além disso, a distribuição em variados tópicos, com gradativa ampliação da abrangência dos temas abordados, parece ter contribuído para a percepção dos professores de que a transposição é possível. De certa forma, a transposição já foi exercida com o próprio professor, ao ser colocado na condição de estudante (cursista) que exercita os conteúdos trabalhados. Tal estratégia didática parece vir ao encontro de recorrentes 
anseios do professor de que é preciso dar visibilidade à relação possível entre teoria e prática.

\subsection{0 que pensam os professores sobre o GESTAR II?}

Três questões objetivaram conhecer a opinião dos participantes quanto a aspectos que julgam positivos e a aspectos a serem repensados do programa. Uma questão buscava a informação sobre qual e quando foi o primeiro contato de cada participante com a teoria dos gêneros.

Dos 10 questionários válidos, classificaram-se as 15 respostas (em alguns questionários o professor menciona duas ou mais referências) em cinco grupos (indicadores).

$\mathrm{Na}$ opinião de todos os sujeitos, o programa apresentou aspectos positivos. Os pontos positivos com maior recorrência foram: material utilizado, possibilidade de aplicação dos conceitos, troca de experiência entre os participantes e a metodologia adotada pelos formadores responsáveis pelo programa. Já quanto aos aspectos a serem repensados na formação, houve um professor que não respondeu esta questão. Dois professores responderam com as expressões: "Nada consta." (professor F) e "A princípio nenhum." (professor I). As sugestões apontadas nas demais respostas foram: aumento do tempo de duração do programa, a organização do trabalho com gêneros por série/ano, mais materiais que viabilizem o trabalho com gêneros nas escolas e a mudança do horário dos encontros (os encontros aconteceram à noite).

A questão "Qual e quando (aproximadamente) foi seu primeiro contato com as discussões sobre gênero textual/discursivo?" foi respondida de forma bastante heterogênea, sendo possível a distribuição em seis grupos.

A resposta mais recorrente (três vezes, totalizando 30\%) foi "No GESTARII". Este é um dado bastante significativo, principalmente ao se considerar que o documento orientador para o ensino de língua portuguesa por meio dos gêneros (PCNs) foi publicado há 11 e 12 anos (considerando os anos 2009 e 2010).

Dois respondentes afirmam que seu primeiro contato com as discussões sobre gênero aconteceu "na faculdade" e ambos mencionam o ano: o professor A entre 1999 e 2003, e o professor D no ano 2000. É interessante ressaltar que a 
formação inicial dos professores ocorreu depois da publicação dos PCNs. Talvez, os professores universitários, atentos ao documento, tenham promovido discussões e possibilitado o acesso dos acadêmicos aos PCNs. A outra recorrência de resposta não especifica uma data para o primeiro contato, apenas menciona que "já trabalhava com os gêneros antes de frequentar o GESTARII”.

Um dos respondentes afirma que "já trabalhava com os gêneros, porém com nomes de textos (crônicas, conto, poema etc.)". Tal resposta dá pistas de uma visão bastante comum entre os professores quando ainda não tão familiarizados com as noções de gênero que é o estabelecimento de uma relação de quase sinonímia entre texto e gênero. Um dos professores, o professor $C$, afirma ter tido seu primeiro contato com as discussões sobre gênero já "no Ensino Médio". Chama a atenção, pois este professor anteriormente informa que concluiu sua graduação em 2000, o que sugere que tenha saído do Ensino Médio quatro anos antes. É provável que este professor tenha participado (enquanto cursava o Ensino Médio) de alguma prática que Ihe remeteu aos gêneros, especialmente os gêneros literários, cujo contato é intensificado neste nível de ensino.

Outro professor, o professor E, afirma que seu primeiro contato aconteceu "Por volta dos anos 96/97. Em cursos desenvolvidos pela Secretaria da Educação." Esta resposta chama a atenção pelos anos informados pelo respondente, anteriores à publicação dos PCNs, que lançaram luz sobre o uso dos gêneros em sala de aula. O professor I, por sua vez, declara que seu primeiro contato com os gêneros aconteceu "A partir da aplicação da Olimpíada da Língua Portuguesa." A Olimpíada acontece em caráter bienal, e foi uma iniciativa do MEC e Fundação Itaú Social, sob a coordenação técnica do Centro de Estudos e Pesquisas em Educação, Cultura e Ação Comunitária (Cenpec). Constitui-se como um programa de formação continuada de professores, sua criação aconteceu em 2002. O material produzido por seus idealizadores é enviado para todas as escolas públicas do país. Neste material há sugestões e sequências didáticas com as quais os professores trabalham para obter a produção escrita dos alunos em quatro diferentes gêneros (trata-se de um gênero diferente para cada grupo de séries/anos) ${ }^{5}$. Esta produção é objeto de análise e premiação nas Olimpíadas.

\footnotetext{
${ }^{5}$ Informações obtidas no site da Olimpíada Escrevendo o Futuro: <http://escrevendo.cenpec.org.br>, acesso em setembro/2012.
} 
De maneira bastante genérica, é possível afirmar que o programa GESTAR foi bem avaliado pelos professores participantes. Como pode ser percebido, o caráter teórico-metodológico do programa contribuiu significativamente para esta análise positiva.

\subsection{Balanço do saber - as concepções sobre gênero}

Fundamentada nas ideias de Charlot (2001), a técnica de coleta de dados denominada "balanço do saber" objetiva que os participantes da pesquisa avaliem seus processos de aprendizagem. Nesta perspectiva, com o intuito de conhecer quais eram as concepções sobre gêneros textuais/discursivos dos professores egressos do GESTAR, construiu-se o seguinte enunciado: "Imagine que, ao voltar da formação continuada GESTAR II, seu supervisor tenha the pedido que repassasse as discussões sobre gêneros textuais para seus colegas de trabalho, o que você diria? E se seus colegas the pedissem para exemplificar com alguma prática já realizada por você, qual você escolheria?".

Nove, dos dez professores, responderam a esta questão. O professor $G$ não respondeu a questão, mas registrou "Segue anexo a Sequência Didática" e enviou o anexo no mesmo envelope em que encaminhou o questionário. Para a análise das respostas, pretende-se, por meio de recorrência de termos (ou ideias), organizar alguns indicadores no sentido de aproximar e confrontar as respostas dos participantes.

\subsection{Sobre as contribuições para o trabalho com o gênero}

Nenhum dos professores iniciou sua exposição trazendo um conceito explícito de gênero. Três professores (professores $A, C$ e F) promovem uma aproximação com aspectos teóricos, como a ideia de situações sociocomunicativas e da estabilidade. $O$ professor A escreve:

O estudo que fizemos sobre o gênero discursivo nos faz ter uma visão mais prática do estudo da língua. Através deles nos comunicamos em diversas situações sociocomunicativas e por isso cabe ao falante da língua conhecer a sua função, o público a quem é dirigido e suas características estruturais. Por exemplo, na minha prática em sala de aula, pude perceber que quando o aluno conhece a função do gênero dentro do seu cotidiano, fica bem mais fácil a sua familiaridade com o mesmo. 
É possível reconhecer parte do discurso do professor A no trecho do material que segue:

Gêneros textuais são maneiras de organizar as informações lingüísticas de acordo com a finalidade do texto, com o papel dos interlocutores e com as características da situação.

Aprendemos a reconhecer e utilizar gêneros textuais no mesmo processo em que "aprendemos" a usar o código lingüístico: reconhecendo intuitivamente o que é semelhante e o que é diferente nos diversos textos.

Do mesmo modo que desenvolvemos uma competência lingüística quando apreendemos o código lingüístico, desenvolvemos uma competência sociocomunicativa quando apreendemos comportamentos lingüísticos. A identificação dos gêneros está incluída nesta competência sociocomunicativa.

Figura 01: Recorte digital do caderno TP3, p. 25

Para o professor C:

há diversos gêneros textuais diversificados e que estamos rodeados por eles. E que não são construídos sobre estruturas rígidas (ou não as possuem) e que apesar de neles existir uma força de estabilidade, estão sujeitos a mudança e intercâmbios com outros gêneros.

No material do programa GESTAR é possível verificar:

Vimos na seção anterior que estabilidade nos gêneros textuais não significa que eles sejam rígidos - estáticos -, mas que seguem uma certo "padrão" de organização.

Figura 02: Recorte digital do caderno TP3, p. 35

Na Seção "Ampliando nossas referências" (TP3, p. 45) aparece o texto intitulado "Gêneros textuais: definição e funcionalidade", de Luiz Antônio Marcuschi (2002), no qual a questão da (não) "rigidez" do gênero também é trazida à tona: 
1. Gêneros textuais como práticas sócio-históricas

Já se tornou trivial a idéia de que os gêneros textuais são fenômenos históricos, profundamente vinculados à vida cultural e social. Fruto de trabalho coletivo, os gêneros contribuem para ordenar e estabilizar as atividades comunicativas do dia-a-dia. São entidades sócio-discursivas e formas de ação social incontornáveis em qualquer situação comunicativa. No entanto, mesmo apresentando alto poder preditivo e interpretativo das ações humanas em qualquer contexto discursivo, os gêneros não são instrumentos estanques e enrijecedores da ação criativa. Caracterizam-se como eventos textuais altamente maleáveis, dinâmicos e plásticos. Surgem emparelhados a necessidades e atividades socioculturais, bem como na relação com inovações tecnológicas, o que é facilmente perceptível ao se considerar a quantidade de gêneros textuais hoje existentes em relação a sociedades anteriores à comunicação escrita.

Figura 03: Recorte digital do caderno TP3, 45

Observando a recorrência de certos termos (sociocomunicativa, função, público, características estruturais, estabilidade) fica evidente no discurso do professor a apropriação de algumas expressões que são acentuadas no material. Vale lembrar, mais uma vez, que o material utilizado na formação é bastante elogiado pelos professores em outras perguntas do mesmo questionário.

$O$ professor $F$, falando da proposta de os gêneros mediarem o ensino de Língua Portuguesa, afirma:

Traz também como vantagem a possibilidade do aluno ser orientado nos mais diversos tipos de texto, podendo lançar mão do gênero que atenderá a situação concreta com qual se deparar no seu dia-a-dia ou porvir.

A perspectiva do uso adequado dos gêneros nas mais distintas situações sociocomunicativas é apontada pelo material do GESTAR II:

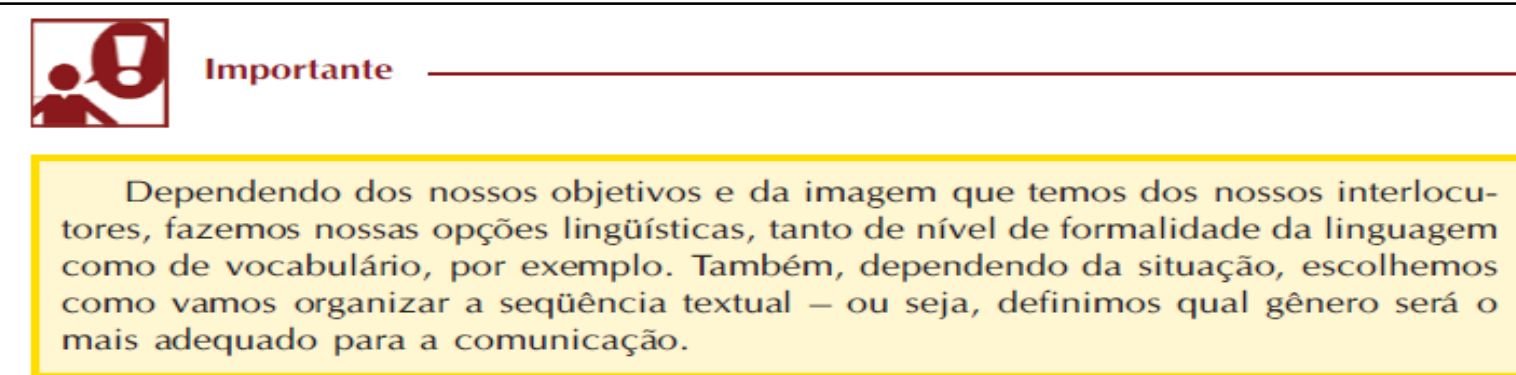

Mas é importante destacar que a maior parte dessas escolhas não é livre: existe uma "história cultural" que nos orienta para que, social e culturalmente, cada um de nós também revele sua posição nas redes sociais em que circula - seus papéis sociais - e de que modos queremos que os outros nos vejam. Essa "escolha" do gênero obedece a hábitos culturalmente construídos e a determinações históricas.

Figura 04: Recorte digital do caderno TP3, p. 29 
Em todas as explicações trazidas por esses professores, com a estratégia de recorrer a termos presentes no material, há um atravessamento dos dizeres de Bakhtin, quando aborda os discursos relativamente estáveis, o contexto sociocomunicativo, as três dimensões do gênero.

Os professores $\mathrm{B}, \mathrm{G}, \mathrm{H}$ e J não apresentaram nenhuma explicação de cunho mais teórico; limitaram-se tão somente a apresentar sua sugestão de atividade, como era solicitado no enunciado. É um fato intrigante, visto que o número de professores que não contextualizam a noção de gênero corresponde a $40 \%$ dos professores pesquisados. Por qual razão os professores optaram por apresentar a sua proposta de trabalho sem algo que pudesse servir como uma justificativa para tal proposta? Será que os professores pressupunham que o "colega" para quem falariam sobre gênero já conhecia os aspectos conceituais a ele relacionados? Talvez esses quatro professores tenham entendido que apenas mencionar 0 exemplo já seria suficiente, ou ainda, esses professores não se sentiram à vontade para fazer uma abordagem mais teórica para contextualizar a sugestão prática. É preciso lembrar que o material do GESTAR apresenta-se como um conjunto de releituras de fontes variadas, algumas apresentadas de modo explícito no material, sem que ocorra um aprofundamento teórico. A superficialidade das discussões não dá condições para uma exposição mais densa de aspectos conceituais.

No caso do professor B, parece perder o foco da resposta tentando justificarse:

Eu tentaria repassar as informações, mesmo sabendo que poderia comprometer a intensidade do tema. Afinal, cursei o Gestar II por um ano e ainda continuo aprendendo sobre gêneros.

Talvez quando esse professor diz que continua aprendendo sobre os gêneros esteja se referindo aos pressupostos de que Imbernón (2010, p. 46) fala: “(...) a formação é um elemento importante de desenvolvimento profissional, mas não é o único e talvez não seja o decisivo."

O professor G, como já apresentado, não respondeu a questão, mas anexou uma sequência didática ao questionário. A sequência não faz menção clara ao conceito de gênero. A única ocorrência em que é possível, indiretamente, enxergar parte da compreensão do professor é quando escreve: "Listar com os alunos, no caderno, as características do Anúncio Publicitário" - referindo-se às características particulares dos gêneros. 
Já o professor $\mathrm{H}$ escreve seu balanço do saber desta forma: "Para uma eventualidade, qualquer gênero: a fábula, por exemplo. Gosto da troca, mas por área." É possível que ele esteja se referindo à troca de experiência, já que no enunciado era possível ler: " $E$ se seus colegas lhe pedissem para exemplificar com alguma prática já realizada por você (...)"

Com relação ao professor J, destaca-se o caráter de "protesto" do texto:

Se fosse dado o tempo para eu elaborar atividades práticas para exemplificar, faria com a melhor da boa vontade. Mas assim como hora extra de graça em casa, não faria. Eu trabalharia inicialmente com o gênero das fábulas, com a diversidade de sua contextualização bem como reforçaria o seu final, a moral.

Para esta análise é preciso lembrar que o professor $\mathrm{J}$ trabalha como professor de Língua Portuguesa há mais de 21 anos, que foi o único professor a manifestar-se em um campo do questionário no qual o preenchimento era facultativo ${ }^{6}$ e não usou o conceito (positivo) máximo para avaliar nenhum dos aspectos abordados no questionário.

Os professores D, E, I também não conceituam gênero de modo explícito, mas, às vezes, é possível inferir suas percepções por meio de termos ou "ideias" usados pelos professores. Para o professor D:

É importante focar a aprendizagem a partir dos gêneros textuais, escolhendo bons textos, preparando uma sequência didática e explorando os aspectos linguísticos e gramaticais adequados ao gênero estudado. É necessário disponibilizar aos alunos vários textos do mesmo gênero e, também, permitir a eles que analisem a intertextualidade.

É interessante refletir sobre o que o professor D pode considerar "bons textos". Seria um resquício do uso tão reforçado em outros tempos de obras clássicas da literatura? Sobre a preparação de uma "sequência didática", ressalta-se que, no material do GESTAR, essa expressão não aparece. Quando há a utilização do termo "sequência", é sempre no sentido de "sequência textual", referindo-se aos tipos de texto. O professor, neste caso, parece colocar na "voz" do material algo que ele não está "dizendo". Isto sugere que há outros discursos atravessando o discurso deste professor, que, muito provavelmente, teve notícia das ideias das sequências

\footnotetext{
${ }^{6}$ Vale lembrar o comentário do professor J sobre o horário das aulas: "Tínhamos que trabalhar o dia inteiro e fazer o curso à noite, deslocando-se diretamente do local de trabalho até o curso. Era muito cansativo."
} 
didáticas em algum outro momento (vale lembrar que o professor G também referencia o uso das sequências didáticas).

Para este professor, "É necessário disponibilizar aos alunos vários textos do mesmo gênero" - esse discurso está bastante presente nos materiais do GESTAR. Para ficar em um exemplo:

6. Se seus alunos já podem interpretar textos mais densos, ou se você preferir trabalhar com outros gêneros, você poderá escolher um dos outros gêneros que foram objeto de nossas reflexões nesta unidade. O importante é que você ofereça aos alunos dois ou mais textos para que as características de um determinado gênero sejam detectadas a partir da comparação entre textos.

Figura 05: Recorte digital do caderno TP3, p. 41

O professor E destaca:

A proposta seria a partir de uma notícia publicada em um jornal e a atividade desenvolvida seria a análise da notícia. Num segundo momento proporia aos meus colegas a análise da estrutura de crônicas do cotidiano e posteriormente a produção de uma crônica a partir da notícia. Para enriquecer a atividade apresentaria o modelo dessa atividade já desenvolvida em sala de aula. Para finalizar seria a socialização dos textos produzidos.

A estrutura da atividade proposta por este professor é facilmente remetida à ideia de sequência didática, como pode ser observado no quadro abaixo.

Por isso, em vez de tipos textuais, vamos chamar de sequiências tipológicas os trechos de um texto que apresentam um certo padrão de organização das estruturas lingüísticas a ponto de identificá-lo como um dos tipos da classificação.

Figura 06: Recorte digital do caderno TP3, p.99

Quando o professor E informa que “apresentaria o modelo" é possível perceber a repetição do discurso presente no material.

3. Apresente um modelo, mesmo que não seja a primeira vez que os alunos fazem esse tipo de trabalho.

Figura 07: Recorte digital do caderno TP2, p. 65

O professor I informa que:

A discussão sobre gêneros textuais é uma nova concepção de trabalhar os textos socialmente usados e sua finalidade. Se o texto não tem uma competência discursiva ou comunicativa, ele não tem razão de ser. 
Vale pensar sobre os motivos que levam este professor a crer que: " $A$ discussão sobre gêneros textuais é uma nova concepção de trabalhar os textos". Primeiramente porque a concepção sobre gênero textual não é nova, mas para o professor I trata-se de algo novo. Ressalta-se que o professor I é professor de Língua Portuguesa há mais de 21 anos. Concluiu o curso de Letras em 1985, e o curso de pós-graduação (especialização) em 1994. Ambas as datas antecedem a publicação dos PCNs; porém, participou do GESTAR em 2010. É possível que esse conjunto de fatores o levou a crer que a discussão sobre a concepção de gênero é nova. Na segunda parte do que o professor I expõe ("Se o texto não tem uma competência discursiva ou comunicativa, ele não tem razão de ser."), infere-se que ele compreendeu a ideia de texto como algo que se dirige a outra pessoa (interlocutor). Essa "visão" de texto é enfatizada no material do GESTAR e remete ao dialogismo, preconizado por Bakhtin.

\subsection{Modos de trabalhar com o gênero}

Já que no enunciado pedia-se a sugestão de uma prática com os gêneros, os professores utilizaram como exemplos diferentes gêneros, de diferentes esferas sociais: crônica (professores $C, D, E$ ), anúncio (professores $A, B, G$ ), fábula (professores $\mathrm{J}, \mathrm{H}$ ), memória (professor F) e notícia de jornal (professor I).

Destaca-se o gênero com maior incidência por um fato interessante: os professores parecem referir-se à mesma atividade com a crônica (trata-se de uma transposição de uma notícia de jornal para a construção de uma crônica); inclusive mencionam o ano/série em que esta atividade poderia ser aplicada ( $9^{\circ}$ ano). É relevante citar que os professores cursaram o GESTAR em períodos diferentes: os professores D e E em 2009 e o professor C em 2010. Em uma busca rápida aos materiais, encontrou-se o gênero crônica com mais recorrência nos cadernos AAA1 e TP1 (que possuem a mesma temática: Linguagem e Cultura); porém, não há a sugestão da transposição, como citado pelos professores. Acredita-se que outro fator relevante na recorrência do gênero crônica é sua utilização habitual no ambiente escolar dada a facilidade com que tais textos podem ali circular, seja em seus suportes reais, seja por meio de reprodução. 
O gênero anúncio, citado por três professores, aparece em cinco dos seis cadernos Teoria e Prática (material usado pelos professores cursistas nos momentos presenciais da formação). Talvez, por ter sido um gênero presente na maior parte do material, os professores o citaram com maior rapidez ou facilidade. Talvez não tenham ainda tido a possibilidade de arriscar com novos gêneros ou de se sentirem motivados a mudar práticas já consolidadas.

A fábula, lembrada por dois professores, é apresentada pelo material nos TPs 2, 3 e 6. Destaca-se o trabalho realizado no TP3, no qual a fábula é foco de algumas atividades. O gênero fábula, além de ter espaço no material do GESTAR, é considerado um gênero escolarizado, por ser trabalhado recorrentemente nas escolas e por estar em algumas páginas de livros didáticos de Língua Portuguesa. A frequência do trabalho escolar e o número considerável de atividades no material da formação podem ter contribuído na opção de resposta desses professores.

$\mathrm{O}$ professor $\mathrm{F}$ sugeriu e exemplificou o trabalho com o gênero memória que não aparece destacado em nenhuma atividade dos cadernos Teoria e Prática. Enfatiza-se sobre a resposta do professor $F$, que, embora o gênero não tenha sido sugerido pelo programa GESTAR, a proposta que esse professor apresenta está claramente fundamentada na perspectiva sociocomunicativa, pois considera aspectos como (nas palavras do professor):

\footnotetext{
[...] a comunidade escolar foi mobilizada a olhar para si mesma, sua história, sua gente, suas raízes, elementos folclóricos, evolução, crítica ao desenvolvimento, dados culturais diversos (moda, música, costumes); a exercitar a oralidade, (entrevista), a resgatar valores, a expressar sentimentos, a usar suportes como mural, jornal, entrevista, a valorizar o idoso, a resgatar palavras e coisas impregnadas desse passado, enfim, uma explosão (ou ao menos um pipocar) de atividades que não seriam pensadas de outra forma ou talvez o fossem de uma maneira isolada e talvez artificial.
}

Ao que parece, o professor F resolveu "arriscar-se" com novos gêneros, ou melhor, com gêneros diferentes dos sugeridos pelo GESTAR.

Por fim, o gênero notícia de jornal foi citado por um professor (professor I). Há recorrências desse gênero em quatro dos seis cadernos TP. Embora seja um número expressivo, na maior parte das vezes a notícia de jornal não é amplamente trabalhada; é apenas citada ou apresenta-se uma proposta de trabalho indireto (por exemplo, ao tratar de poética, um dos cadernos (TP3, p. 192) traz o "Poema tirado 
de uma notícia de jornal" com o intuito de demonstrar que "um tema cotidiano pode ter tratamento poético e compor um gênero literário." O professor I justifica a escolha por esse gênero: "[...] eu escolheria a notícia de jornal, por se tratar de um texto acessível a todas as camadas sociais e fácil compreensão."

\subsection{Discursos dissonantes...}

A sugestão da organização do trabalho do professor por meio da sequência didática não aparece claramente nem nos PCNs, nem no material do GESTAR, mas ainda assim é citada/exemplificada por um dos professores.

Com relação à sequência didática mencionada, vale lembrar que foi anexada ao questionário do professor G. A sequência é dividida em 12 subdivisões: (1) Fundamentação teórica - o professor conceitua alguns termos como propaganda, anúncio e publicidade; (2) Objetivo específico - há menção de um objetivo ("Inteirarse do gênero anúncio"); (3) Objetivos gerais - nesta seção o professor registra nove objetivos (exemplo: "Posicionar-se criticamente como consumidor do produto anunciado"); (4) Apresentação aos alunos - o professor, de maneira sucinta, explica como se desenvolverá o trabalho; (5) Conhecimentos prévios - há seis perguntas que, infere-se, o professor fará aos alunos (exemplo: "Propaganda e anúncio publicitário é a mesma coisa?'); (6) Ampliação de repertório - nesta seção, o professor expõe os sete arquivos de anúncios publicitários que apresentará aos alunos; ao final de cada descrição, há um conjunto de perguntas que, novamente infere-se, o professor fará aos alunos; (7) Marcas do gênero - o professor destaca cinco características de um anúncio; (8) Informações sobre o tema: alimentação saudável - neste item o professor apenas descreve: "Ver anexo" (ressalta-se que a sequência enviada não possuía anexo); (9) Produzir um texto coletivo - o professor propõe a construção coletiva de um anúncio "em tamanho grande."; (10) Produzir um texto individual ou em dupla - o professor informa que a produção será exposta na escola e que abordará o cuidado com a alimentação; (11) Revisão e Reedição o professor sugere que antes da reescrita haja "recuperação das características do gênero."; (12) Publicação dos anúncios - nesta seção há, novamente, a informação

\footnotetext{
${ }^{7}$ Do autor Manuel Bandeira.
} 
de que os anúncios serão expostos na escola e que um dos anúncios será selecionado para publicação no Jornal do Bairro ou ANEscola ${ }^{8}$. Por fim, o professor apresenta as referências utilizadas para a fundamentação teórica, nas quais constam apenas ${ }^{9}$ o livro: Português: Linguagens e endereços de sites, dos quais foram retirados os anúncios usados na atividade proposta. Acredita-se que seja o livro didático usado pela turma em questão.

A estrutura de sequência didática usada pelo professor $G$ pode ser relacionada ao modelo proposto por Dolz, Schneuwly e Colaboradores (2004).

Ao observar a resposta escrita pelo professor G ("Segue anexo a Sequência Didática") é possível fazer algumas reflexões: o que pode ter levado esse professor a anexar uma sequência ao invés de responder diretamente a questão? Os discursos de diferentes espaços podem ter se cruzado, se fundido na fala desse professor, até porque não é mais iniciante, ou seja, já têm significativa trajetória.

\section{ALGUMAS CONSIDERAÇÕES}

A principal intenção desta pesquisa foi constatar as percepções de professores de Língua Portuguesa sobre o GESTAR II e sua contribuição para o trabalho com os gêneros textuais/discursivos em sala de aula. Sob esta questão, recaem dois importantes focos: a formação continuada como desenvolvimento do profissional docente e o gênero textual/discursivo como uma proposta para o trabalho com Língua Portuguesa.

O programa GESTAR foi, de forma geral, bem avaliado pelos dez professores de Língua Portuguesa, egressos do programa, que se configuraram como sujeitos do estudo aqui apresentado. Como aspectos "a serem repensados" no programa os professores sugerem: maior tempo de duração do programa, a organização dos gêneros por série/ano, que haja mais materiais nas escolas e que o horário dos encontros seja repensado (os encontros ocorriam à noite). Parecem não mais aceitar a ideia de que trabalham "por dom, vocação, ou amor" e por isso, negam uma formação que ultrapasse seu expediente.

\footnotetext{
${ }^{8}$ ANEscola é um caderno mensal veiculado pelo jornal regional ANotícia. O caderno apresenta trabalhos realizados por escolas públicas da cidade e região.

${ }^{9}$ As outras referências dizem respeito às informações sobre anúncio publicitário, por isso destacou-se a única referência que trata do trabalho com a língua.
} 
Sobre o GESTAR destacam-se dois pontos: o material utilizado e o caráter teórico-prático do programa. Há claras orientações sobre como desenvolver as atividades propostas no próprio material, e é sob essa perspectiva que os professores conceituam o material como "muito bom".

Em diferentes momentos na coleta de dados, foi possível perceber o quanto os professores valorizaram o GESTAR por sua característica teórico-prática. O aspecto "troca de experiência" foi bastante mencionado e elogiado, os professores expõem abertamente o crescimento profissional a partir desse tipo de atividade. É importante trazer para esse contexto a noção de prática como um espaço de "construção de saberes". Para Tardif:

Se assumirmos o postulado de que os professores são atores competentes, sujeitos ativos, deveremos admitir que a prática deles não é somente um espaço de aplicação de saberes provenientes da teoria, mas um espaço de produção de saberes específicos oriundos dessa mesma prática. (2002, p. 234).

Embora a troca de experiência tenha sido evidenciada como aspecto positivo pelos professores, estes também afirmam a preocupação com o contexto histórico e social dos estudantes para que o trabalho com gêneros seja significativo. É interessante perceber que em significativa parte das respostas dos professores é possível constatar o atravessamento do que está posto no material do GESTAR. Ao que parece, os professores egressos da formação compreendem o "discurso" do material e se apropriam dele.

O conceito de gênero textual/discursivo é tangenciado por apenas três (dos dez) professores, quando são convidados a sugerir o modo pelo qual repassariam aos colegas aquilo que viram no Programa. Outros três professores se apropriam de termos empregados no material, mas sem aprofundar as questões que contextualizariam teoricamente as práticas propostas. $\mathrm{E}$ os outros quatro professores apenas sugeriram uma atividade prática, como era solicitado na segunda parte do enunciado, sem expor as discussões sobre gênero do programa.

Com relação aos dizeres dos professores sobre gênero, constantemente é possível reconhecer, em seus discursos, ideias e expressões encontradas no material do GESTAR. Os professores, ao tratar das discussões e conceito do 
gênero, demonstram preocupação com a competência sociocomunicativa (apontada no material e pressuposta por Bakhtin).

Uma das principais contribuições deste estudo reside na percepção dos professores a respeito da contribuição de uma formação continuada.

Os dados obtidos com esta pesquisa permitem apontar algumas sugestões sobre o tema:

- que a formação continuada não seja apenas um "item" a ser somado no plano de carreira dos professores;

- que as formações continuadas priorizem relações com o fazer pedagógico, de maneira reflexiva;

- que os professores sejam ouvidos e que possam ser "protagonistas" das formações continuadas;

- que os professores contem com o apoio dos formadores, mesmo depois de concluída a formação, pois às vezes o distanciamento das discussões pode gerar questionamentos;

- que haja constante avaliação das formações propostas, e que se considerem também os dizeres dos professores participantes.

\section{LEILA MATTOS SOMBRIO}

Mestre em Educação pela Universidade da Região de Joinville, professora do Ensino Fundamental.

\section{ROSANA MARA KOERNER}

Doutora em Linguística Aplicada à Língua Materna, professora nos Cursos de Letras e de Pedagogia e no Mestrado em Educação da Universidade da Região de Joinville.

\section{REFERÊNCIAS}

ANDRÉ, M. Formação de professores: um campo de estudos. Revista de Educação da Pontifícia Universidade Católica do Rio Grande do Sul - PUC RS. Porto Alegre, v. 33, n. 3, set/dez de 2010, p. 174-181. Disponível em: <http://revistaseletronicas.pucrs.br/ojs/index.php/faced>. Acesso em: 19/04/2011.

Campinas, SP: Papirus, 2001. 
BAKHTIN, M. Estética da criação cerbal. Tradução de Maria Ermantina Galvão G. Pereira. 3. ed. São Paulo: Martins Fontes, 2003 [1952, 1953].

BARDIN, L. Análise de conteúdo. Lisboa: Edições 70, 1977.

BRAIT, B. PCNs, gêneros e ensino de língua: faces discursivas da textualidade. In: ROJO, R (Org.). A prática da linguagem em sala de aula: praticando os PCN's. Campinas-SP: Mercado de Letras, 2000, p.15-25.

BRASIL. Programa Gestão da Aprendizagem Escolar - GESTAR II, Guia Geral, Brasília: MEC/SEB, 2008.

BRASIL. Programa Gestão da Aprendizagem Escolar - GESTAR II, Cadernos Atividades de Apoio à Aprendizagem, Brasília: MEC/SEB, 2008.

BRASIL. Programa Gestão da Aprendizagem Escolar - GESTAR II, Cadernos Teoria e Prática, Brasília: MEC/SEB, 2008.

BRASIL. Lei NN 9.394, de 20 de dezembro de 1996 Lex: Leis de Diretrizes e Bases da educação Brasileira (LDB), Brasília, 1996.

BRASIL. Ministério da Educação. Parâmetros curriculares nacionais - Ensino fundamental - Língua Portuguesa. Brasília: SEF/MEC, 1998.

CHARLOT, B. et al. (Org.). Os jovens e o saber perspectivas mundiais. Tradução de Fátima Murad. Porto Alegre: Artmed, 2001.

DOLZ, J.; SCHNEUWLY, B. e colaboradores. Os gêneros orais e escritos na escola. Campinas-SP: Mercado de Letras, 2004.

GATTI, B.; ANDRÉ, M. A relevância dos métodos de pesquisa qualitativa em Educação no Brasil. In: WELLER, W.; PFAFF, N. (Orgs.). Metodologias da pesquisa qualitativa em educação. Petrópolis: Vozes, 2010, p. 29-38.

GATTI, B. A. Análise das políticas públicas para formação continuada no Brasil, na última década. Revista Brasileira de Educação. v. 13, n.37, jan./abr. 2008, p. 5770.

IMBERNÓN, F. Formação docente e profissional: formar-se para a mudança e a incerteza. 2. ed. São Paulo: Cortez, 2001.

. Formação continuada de professores. Tradução de Juliana dos Santos Padilha. Porto Alegre: Artmed, 2010.

LIBÂNEO, J. C. Organização e gestão escolar teoria e prática. 5.ed. Goiânia: Alternativa, 2004. 
MARCUSCHI, L. A. Gêneros textuais: definição e funcionalidade. In: DIONÍSIO, A. P.; MACHADO, A.R.; BEZERRA, M.A. (Orgs.) Gêneros textuais e ensino. 2. ed. Rio de Janeiro: Lucerna, 2003. p. 19-36.

NÓVOA, A. Formação de professores e trabalho pedagógico. Lisboa/Portugal: Educa, 2002.

RODRIGUES, R.H. Os gêneros do discurso na perspectiva dialógica da linguagem: a abordagem de Bakhtin. In: MEURER, J. L.; BONINI, A.; MOTTA-ROTH, D. (Orgs.). Gêneros: teorias, métodos, debates. 2.ed. São Paulo: Parábola, 2005, p. 152-183.

SCHNEUWLY, B.; DOLZ, J. Os gêneros escolares: das práticas de linguagem aos objetos de ensino. Revista Brasileira de Educação. [online]. 1999, n.11, p. 05-16. Disponível em:

<http://educa.fcc.org.br/scielo.php?script=sci_abstract\&pid=S1413247819990002000 02\&lng=pt\&nrm=iso $>$. Acesso em: 07/09/2011

TARDIF, M.; LESSARD, C. 0 trabalho docente: elementos para uma teoria da docência como profissão de interações humanas. Tradução de João Batista Kreuch. Petrópolis, RJ: Vozes, 2005.

VASCONCELLOS, C. dos S. Coordenação do trabalho pedagógico: do projeto político ao cotidiano da sala de aula. São Paulo: Libertad, 2006. 